\title{
EVALUASI FAKTOR-FAKTOR YANG MEMPENGARUHI KINERJA KEUANGAN (STUDI KASUS LIPPO KARAWACI TBK)
}

\author{
Latifah Wulandari Binti Asbaruna
}

Bisnis Digital, Universitas Ma'soem

latifahwulandariasbaruna@gmail.com

Ridwan Ismail Gorib

Bisnis Digital, Universitas Ma'soem

ridwanismail0@gmail.com

Dadang Husen Sobana

Manajemen Keuangan Syariah, UIN Sunan Gunung Djati Bandung

dadanghusensobana@uinsgd.ac.id

\section{Abstrak}

Tujuan penelitian ini adalah mengevaluasi faktor-faktor yang mempengaruhi kinerja keuangan di PT. Lippo Karawaci Tbk. Metode penelitian yang digunakan adalah studi kasus, pengumpulan data, mempelajari literatur, media cetak dan internet untuk diolah, dianalisis dan diambil kesimpulan, dalam rangka memperoleh gambaran secara sistematis akan kinerja keuangan perusahaan. Hasil penelitian menunjukan Kinerja keuangan perusahaan Lippo Karawaci Tbk hampir keseluruhan mengalami kondisi kurang baik. Tingkat current ratio, debt to equity ratio, return on equity dan Perputaran modal kerja pada perusahaan Lippo Karawaci cenderung tidak stabil. Penurunan current ratio disebabkan oleh peningkatan utang lancar lebih besar dibandingkan dengan peningkatan aktiva lancar. Untuk DER pada tahun 2019 kondisi struktur modal pada perusahaan baik hal ini ditunjukkan oleh DER sebesar $60 \%$ karena rasio rata - rata debt to equity sebesar $80 \%$. Untuk penurunan return on equity disebabkan oleh besarnya modal sendiri tanpa disertai kenaikan laba bersih yang tinggi. Begitu juga dengan rasio perputaran modal kerja, untuk dapat lebih meningkatkan tingkat perputaran modal kerja, pihak perusahaan harus dapat lebih meningkatkan tingkat pendapatannya.

\section{Kata Kunci: Evaluasi, Faktor-Faktor yang Mempengaruhi, Kinerja Keuangan}

\begin{abstract}
The ratio used to measure the company in generating profit is the rate of return on assets. The profit generated by the company can be known through financial statement analysis measurement tools, one of which is the current ratio and debt ratio. This research was conducted with the aim of knowing and analyzing the effect of the current ratio and debt ratio on the rate of return on assets of PT. Jakarta International Hotels \& Development (JIHD) either partially or simultaneously. So that the research method used is descriptive verification method and quantitative approach, with data analysis techniques using quantitative analysis consisting of simple and multiple regression tests, PPM correlation, coefficient of determination, and bypothesis testing. The research data is sourced from secondary data which is obtained from the annual financial report of PT. Jakarta International Hotels \& Development (JIHD). The results showed that partially only the current ratio had an effect on the rate of return on assets with an effect of $66 \%$, while the debt ratio had no effect. Finally, the current ratio and debt ratio simultaneously affect the rate of return on assets with an effect of $66.3 \%$.
\end{abstract}

Keywords: Evaluation, Factors, Influencing, Financial Performance 


\section{Pendahuluan}

Sektor properti dan real estate menarik minat investor dikarenakan pertambahan jumlah penduduk serta bertambahnya kebutuhan manusia akan tempat tinggal, perkantoran, pusat perbelanjaan, dan lain-lain. Pemerintah juga memberikan perumahan subsidi dan bantuan perbankan melalui KPR (Kredit Kepemilikan Rumah) untuk penduduk Indonesia agar penduduk Indonesia lebih mudah untuk memiliki rumah, menjadikan penjualan pada sektor properti semakin meningkat setiap tahunnya. Lippo Karawaci Tbk, merupakan salah satu perusahaan properti dan real estate. Dalam menjaga kondisi keuangan, Lippo Karawaci Tbk perlu mengkaji kinerjanya melalui kinerja keuangannya.

Melakukan analisis kinerja keuangan untuk mengetahui sejauh mana efektivitas operasi perusahaan dalam mencapai tujuannya dan menilai kinerja perusahaan dapat menggunakan analisis rasio, yang dimulai dengan mencari hubungan berbagai pos dalam laporan keuangan, yaitu dengan menggunakan laporan keuangan yang diperbandingkan, termasuk data tentang perubahan-perubahan yang terjadi dalam jumlah rupiah, prosentasi, dan trendnya. Rasio tersebut akan menggambarkan suatu hubungan atau pertimbangan antara suatu jumlah tertentu dengan jumlah yang lain, analisis rasio juga dapat menjelaskan atau memberi gambaran tentang baik atau buruknya kondisi keuangan suatu perusahaan.

Untuk mengetahui apakah perusahaan sudah berjalan dengan baik, maka diketahui kinerja perusahaannya. Kinerja perusahaan secara sederhana dapat diketahui dari tiga hal (Sutrisno, 2003); (a) likuiditas, yang merupakan kemampuan perusahaan untuk memenuhi kewajiban-kewajibannya yang harus segera dipenuhi; (b) solvabilitas, yaitu kemampuan perusahaan untuk memenuhi semua kewajibannya apabila perusahaan dilikuidasi; dan (c) rentabilitas, yang merupakan kemampuan perusahaan untuk menghasilkan laba selama periode tertentu.

Untuk mengetahui bagaimana kinerja keuangan perusahaan selama periode 2018-2020, maka dapat dinilai meliputi rasio-rasio keuangan Current Ratio, Debt to equity ratio, Return On Equity dan Perputaran Modal Kerja. Berikut ini adalah tabel perkembangan kinerja keuangan Lippo Karawaci Tbk selama periode 2018-2020 :

Tabel 1.1

Perkembangan Kinerja Keuangan Lippo Karawaci Tbk periode 2018-2020

\begin{tabular}{|c|c|c|c|c|}
\hline \multirow{2}{*}{ No } & Rasio & Tahun & Nilai & $\begin{array}{c}\text { Perubahan } \\
\text { (N/T) }\end{array}$ \\
\hline \multirow{2}{*}{1} & Current Ratio & 2018 & 4.03 & 0 \\
\cline { 3 - 5 } & & 2019 & 5.41 & 1,38 \\
\cline { 3 - 5 } & & 2020 & 3.86 & $(1,54)$ \\
\hline \multirow{2}{*}{2} & \multirow{2}{*}{ Debt to equity ratio } & 2018 & $98 \%$ & 0 \\
\cline { 3 - 5 } & & 2019 & $60 \%$ & $(38 \%)$ \\
\cline { 3 - 5 } & & 2020 & $94 \%$ & $34 \%$ \\
\hline \multirow{2}{*}{3} & \multirow{2}{*}{ Return On equity } & 2018 & $6.7 \%$ & 0 \\
\cline { 3 - 5 } & & 2019 & $-6.0 \%$ & $(12,7 \%)$ \\
\hline \multirow{2}{*}{4} & \multirow{3}{*}{ Perputaran Modal Kerja } & 2020 & $-6.1 \%$ & $(0,1 \%)$ \\
\cline { 3 - 5 } & & 2018 & 0.46 & 0 \\
\cline { 3 - 5 } & & 2019 & 0.41 & $(0,05) \mathrm{kali}$ \\
\hline
\end{tabular}

Sumber : Laporan Keuangan Lippo Karawaci Tbk Th. 2018-2020

Berdasarkan tabel perkembangan kinerja keuangan Lippo Karawaci Tbk dapat diketahui bahwa selama (tiga) tahun yaitu dari tahun 2018 hingga tahun 2020 mengalami fluktuatif setiap tahunnya namun sebagian besar mengalami penurunan. Berdasarkan uraian-uraian di atas, maka 
penulis tertarik untuk melakukan penelitian dengan judul, "Evaluasi Faktor-Faktor yang Mempengaruhi Kinerja Keuangan (Studi Kasus pada Lippo Karawaci Tbk)". Adapun pertanyaan yang disajikan dari latar belakang diatas penulis mengidentifikasi masalah sebagai berikut : Faktor-faktor apa saja yang mempengaruhi pencapaian kinerja keuangan (Rasio Likuiditas, Rasio Leverage, Rasio Manajemen Asset, Rasio Profitabilitas) di Lippo Karawaci Tbk.)?

Berdasarkan identifikasi masalah diatas penelitian ini mempunyai maksud dan tujuan sebagai berikut: untuk mengevaluasi faktor-faktor yang mempengaruhi kinerja keuangan di Lippo Karawaci Tbk.

\section{Metode Penelitian}

Metode penelitian yang digunakan deskriptif analitis. Dalam hal ini peneliti mendeskripsikan dan menganalisis variabel dan faktor yang mempengaruhinya dalam menilai kinerja keuangan PT. Lippo Karawaci, Tbk. Kemudian, jenis data yang digunakan adalah data sekunder. Menurut sugiyono (2010:193) "Data sekunder adalah data yang tidak langsung diberikan pada pengumpul data, data ini diperoleh dari buku-buku, arikel tulisan ilmiah serta situs-situs internet yang berkenaan dengan penelitian yang dilakukan". Maka dari itu, sumber data yang digunakan dalam penelitian ini adalah data keuangan Lippo Karawaci Tbk tahun 2018-2020 yang diambil dari laporan tahunan yang dipublikasikan dari website resmi Bursa Efek Indonesia (BEI) yaitu www.idx.co.id. Teknik pengumpul data dalam penelitian ini studi literatur yang berhubungan langsung dengan objek penelitian dan judul penelitian, melalui buku-buku, media cetak dan internet.

Sesuai dengan judul penelitian yaitu "Evaluasi Faktor-Faktor Yang Mempengaruhi Kinerja Keuangan”, maka variabel dalam penelitian ini dapat dilihat pada tabel :

Tabel 1 Operasionalisasi variabel

\begin{tabular}{|l|l|l|}
\hline \multicolumn{1}{|c|}{ Variabel } & \multicolumn{1}{|c|}{ Sub Variabel } & \multicolumn{1}{c|}{ Indikator } \\
\hline $\begin{array}{l}\text { Faktor-faktor yang } \\
\text { mempengaruhi Kinerja }\end{array}$ & Current ratio & $\begin{array}{l}\text { a. Aktiva Lancar } \\
\text { Keuangan }\end{array}$ \\
\cline { 2 - 3 } & Debt to equity ratio & $\begin{array}{l}\text { a. Total Hutang } \\
\text { b. Modal Sendiri }\end{array}$ \\
\cline { 2 - 3 } & Return On Equity & $\begin{array}{l}\text { a. Laba Bersih setelah pajak } \\
\text { b. Equity }\end{array}$ \\
\cline { 2 - 3 } & Perputaran Modal Kerja & $\begin{array}{l}\text { a. Penjualan } \\
\text { b. Modal Kerja Rata-Rata }\end{array}$ \\
\hline
\end{tabular}

Untuk menjawab identifikasi masalah yaitu Faktor-faktor apa saja yang mempengaruhi pencapaian kinerja keuangan (Rasio Likuiditas, Rasio Leverage, Rasio Manajemen Asset, Rasio Profitabilitas), maka digunakan analisis deskriptif dengan melihat keadaan kinerja keuangan dari masing-masing rasio yang telah dihitung menggunakan alat analisis trend.

Tabel 2. Perkembangan Current Ratio

\begin{tabular}{|c|c|c|c|c|c|c|}
\hline Tahun & $\begin{array}{c}\text { Aktiva Lancar } \\
\text { (Rp) }\end{array}$ & $\begin{array}{c}\text { N/T } \\
(\%)\end{array}$ & $\begin{array}{c}\text { Utang Lancar } \\
\text { (Rp) }\end{array}$ & $\begin{array}{c}\text { N/T } \\
(\%)\end{array}$ & Current Ratio & $\begin{array}{c}\text { N/T } \\
(\%)\end{array}$ \\
\hline 2008 & & & & & & \\
\hline 2019 & & & & & & \\
\hline 2020 & & & & & & \\
\hline
\end{tabular}


Tabel 3. Perkembangan Debt to equity ratio

\begin{tabular}{|c|c|c|c|c|c|c|}
\hline Tahun & $\begin{array}{c}\text { Total Hutang } \\
(\mathrm{Rp})\end{array}$ & $\begin{array}{c}\mathrm{N} / \mathrm{T} \\
(\%)\end{array}$ & $\begin{array}{c}\text { Modal Sendiri } \\
(\mathrm{Rp})\end{array}$ & $\begin{array}{c}\mathrm{N} / \mathrm{T} \\
(\%)\end{array}$ & $\begin{array}{c}\text { DER } \\
(\%)\end{array}$ & $\begin{array}{c}\mathrm{N} / \mathrm{T} \\
(\%)\end{array}$ \\
\hline 2018 & & & & & & - \\
\hline 2019 & & & & & & \\
\hline 2020 & & & & & & \\
\hline
\end{tabular}

Tabel 4. Perkembangan Return On Equity

\begin{tabular}{|c|c|c|c|c|c|c|}
\hline Tahun & $\begin{array}{c}\text { Laba Bersih setelah pajak } \\
(\mathrm{Rp})\end{array}$ & $\begin{array}{c}\mathrm{N} / \mathrm{T} \\
(\%)\end{array}$ & $\begin{array}{c}\text { Equity } \\
(\mathrm{Rp})\end{array}$ & $\begin{array}{c}\mathrm{N} / \mathrm{T} \\
(\%)\end{array}$ & $\begin{array}{c}\text { Return On } \\
\text { Equity } \\
(\%)\end{array}$ & $\begin{array}{c}\mathrm{N} / \mathrm{T} \\
(\%)\end{array}$ \\
\hline 2018 & & & & & & \\
\hline 2019 & & & & & & \\
\hline 2020 & & & & & & \\
\hline
\end{tabular}

Tabel 5. Perkembangan Perputaran Modal Kerja

\begin{tabular}{|c|c|c|c|c|c|c|}
\hline Tahun & $\begin{array}{c}\text { Penjualan } \\
\text { (Rp) }\end{array}$ & $\begin{array}{c}\text { N/T } \\
(\%)\end{array}$ & $\begin{array}{c}\text { Rata-rata MK } \\
(\mathrm{Rp})\end{array}$ & $\begin{array}{c}\text { N/T } \\
(\%)\end{array}$ & $\begin{array}{c}\text { Perputaran MK } \\
(\%)\end{array}$ & $\begin{array}{c}\text { N/T } \\
(\%)\end{array}$ \\
\hline 2018 & & & & & & \\
\hline 2019 & & & & & & \\
\hline 2020 & & & & & & \\
\hline
\end{tabular}

\section{Hasil dan Pembahasan}

Berdasarkan identifikasi masalah yang telah dikemukakan, maka akan dibahas masingmasing identifikasi masalah berdasarkan rancangan analisis yaitu faktor-faktor yang mempengaruhi keinerja keuangan dilihat dari Rasio Likuiditas, Rasio Leverage, Rasio Manajemen Asset, Rasio Profitabilitas.

\subsection{Faktor-faktor yang Mempengaruhi Rasio Likuiditas}

Menurut Djudju Djuhana (2009) "Rasio likuiditas yaitu kemampuan perusahaan membayar kewajiban jangka pendek meliputi current ratio, quick ratio, dan net working capital'. Rasio likuiditas yang digunakan dalam penelitian ini adalah current ratio. Current ratio merupakan rasio yang paling umum dan lazim digunakan untuk mengukur likuiditas suatu perusahaan (Munawir, 2007). Menurut Djuju Djuhana (2009) “Current ratio menunjukkan aktiva lancar yang dimiliki emiten dalam membayar kewajiban jangka pendek, semakin rasio maka semakin baik".

Tabel 6. Perkembangan Current Ratio

\begin{tabular}{|c|c|c|c|c|c|c|}
\hline Tahun & $\begin{array}{c}\text { Aktiva Lancar } \\
(\mathrm{Rp})\end{array}$ & $\begin{array}{c}\mathrm{N} / \mathrm{T} \\
(\%)\end{array}$ & $\begin{array}{c}\text { Utang Lancar } \\
(\mathrm{Rp})\end{array}$ & $\begin{array}{c}\text { N/T } \\
(\%)\end{array}$ & Current Ratio & $\begin{array}{c}\mathrm{N} / \mathrm{T} \\
(\%)\end{array}$ \\
\hline 2008 & $\mathrm{Rp} 33.046 .000 .000 .000$ & - & $\mathrm{Rp} 8.205 .000 .000 .000$ & - & 4.03 & - \\
\hline 2019 & $\mathrm{Rp} 37.197 .000 .000 .000$ & 13 & $\mathrm{Rp} 6.881 .000 .000 .000$ & $(16)$ & 5.41 & 1.38 \\
\hline 2020 & $\mathrm{Rp} 39.189 .618 .000 .000$ & 5 & $\mathrm{Rp} 10.149 .292 .000 .000$ & 47 & 3.86 & $(1.55)$ \\
\hline
\end{tabular}

Sumber : Laporan Keuangan Lippo Karawaci Tbk Th. 2018-2020

Berdasarkan tabel perkembangan Current ratio dari tahun 2018 sampai dengan tahun 2020 mengalami fluktuasi, adanya peningkatan current ratio yaitu terjadi pada tahun 2019 sebesar 5,41 kali. Artinya jumlah aktiva lancar sebanyak 5,4 kali utang lancar, atau setiap 1 rupiah utang lancar dijamin oleh 5,4 rupiah harta lancar atau 5,4:1 antara aktiva lancar dengan utang lancar. Pada tahun 2020 current ratio mengalami penurunan. Faktor yang menyebabkan adanya 
penurunan current ratio pada tahun 2020 yaitu disebabkan oleh peningkatan utang lancar lebih besar dibandingkan dengan peningkatan aktiva lancar. Penurunan pada Current ratio bisa disebabkan oleh dua hal, faktor yang pertama adanya kelebihan investasi pada aktiva perusahaan yang berarti ketidakmampuan perusahaan dalam memaksimalkan penjualannya.

Kedua adalah apabila perusahaan telah dapat meningkatkan penjualannya, maka faktor yang dapat menyebabkan penurunan likuiditasnya adalah ketidakmampuan perusahaan dalam mengontrol efisiensi penggunaan dana/biaya yang telah dikeluarkan oleh perusahaan untuk menghasilkan penjualan tersebut. Hal ini dikarenakan setelah perusahaan dapat meningkatkan proporsi penjualannya, perusahaan tidak dapat mengontrol penggunaan biaya yang dikeluarkan sehingga proporsi laba yang diperoleh perusahaan semakin mengecil. Kecenderungan tingkat likuiditas yang tinggi menunjukkan kemampuan likuiditas yang baik namun juga dapat megindikasikan adanya inefisiensi dan modal yang tidak didayagunakan dengan maksimal.

Dapat dikatakan terdapat inefisiensi dan kemampuan mengelola modal kerja belum maksimal. Rasio likuiditas yang tinggi selama tiga tahun menunjukkan adanya kemampuan untuk membayar kewajiban jangka pendek. Nilai rasio yang tinggi juga menunjukkan besarnya dana yang diinvestasikan dalam aktiva lancar.

\subsection{Faktor-Faktor yang Mempengaruhi Rasio Leverage}

Menurut Werner R (2013) Rasio Leverage "merupakan rasio yang menggambarkan kemampuan perusahaan dalam mengelola dan melunasi kewajibannya." Rasio Leverage yang digunakan dalam penelitian ini adalah Debt to equity ratio. Menurut Susan (2006) Debt to equity ratio "merupakan rasio yang digunakan untuk mengukur perimbangan antara kewajiban yang dimiliki perusahaan dengan modal sendiri."

Rasio Leverage adalah rasio yang digunakan untuk mengukur seberapa aset yang dimiliki perusahaan berasal dari hutang atau modal. Dalam penelitian ini jenis rasio yang dipakai untuk mengukur rasio Leverage adalah Debt to equity ratio. Debt to equity ratio menggambarkan sampai sejauh mana modal pemilik dapat menutupi hutang-hutang kepada pihak luar dan merupakan rasio yang mengukur hingga sejauh mana perusahaan dibiayai dari hutang. Berikut ini adalah tabel perkembangan Debt to equity ratio:

Tabel 7. Perkembangan Debt to equity ratio

\begin{tabular}{|c|c|c|c|c|c|c|}
\hline Tahun & $\begin{array}{c}\text { Total Hutang } \\
(\mathrm{Rp})\end{array}$ & $\begin{array}{c}\mathrm{N} / \mathrm{T} \\
(\%)\end{array}$ & $\begin{array}{c}\text { Modal Sendiri } \\
(\mathrm{Rp})\end{array}$ & $\begin{array}{c}\text { N/T } \\
(\%)\end{array}$ & $\begin{array}{c}\text { DER } \\
(\%)\end{array}$ & $\begin{array}{c}\text { N/T } \\
(\%)\end{array}$ \\
\hline 2018 & $\mathrm{Rp} 24.336 .000 .000 .000$ & - & $\mathrm{Rp} 24.747 .000 .000 .000$ & - & $98 \%$ & - \\
\hline 2019 & $\mathrm{Rp} 20.703 .000 .000 .000$ & $(15)$ & $\mathrm{Rp} 34.377 .000 .000 .000$ & 39 & $60 \%$ & $(0.38)$ \\
\hline 2020 & $\mathrm{Rp} 29.962 .905 .000 .000$ & 45 & $\mathrm{Rp} 31.871 .516 .000 .000$ & $(7)$ & $94 \%$ & 0.34 \\
\hline
\end{tabular}

Sumber : Laporan Keuangan Lippo Karawaci Tbk Th. 2018-2020

Pada tahun 2018 merupakan tahun dasar penelitian ini dan menunjukkan DER sebesar 98\% hal ini menunjukkan bahwa kondisi struktur modal pada tahun 2018 kurang baik, karena jika rasio rata - rata debt to equity sebesar $80 \%$ perusahaan masih dianggap kurang baik karena berada diatas rata-rata. Namun pada tahun 2019 kondisi struktur modal pada perusahaan baik hal ini ditunjukkan oleh DER sebesar 60\% dan meningkatnya jumlah modal sendiri yang lebih besar dibandingkan dengan kenaikan total hutang, sehingga pada tahun 2019 perusahaan memiliki nilai DER yang menurun. Dari penjelasan di atas dapat disimpulkan bahwa peru- 
sahaan pada tahun 2019 telah lebih baik, karena kondisi DER mengalami penurunan dan jumlah modal sendiri lebih besar dari pada total hutang yang dimiliki perusahaan. Pada tahun 2020 total hutang mengalami kenaikan yaitu sebesar 29.962.905.000.000 artinya pada tahun 2020 adanya kenaikan total hutang yang lebih besar. Dari penjelasan di atas dapat disimpulkan bahwa perusahaan secara keseluruhan dari tahun 2018 sampai 2020 cukup stabil, walaupun kondisi DER mengalami penurunan dan kenaikan dilihat dari tabel di atas.

\subsection{Faktor-Faktor yang Mempengaruhi Rasio Profitabilitas}

Menurut Kasmir (2008) Rasio Profitabilitas "merupakan rasio untuk menilai kemampuan perusahaan dalam mencari keuntungan". Rasio profitabilitas yang digunakan dalam penelitian ini adalah Return On Equity. Menurut Susan (2006) menyatakan bahwa: "Return on Equity adalah rasio yang digunakan untuk mengukur kemampuan suatu perusahaan dalam menghasilkan laba bersih dari modal sendiri yang digunakan oleh perusahaan tersebut, sehinggaa ROE ini ada yang menyebut sebagai rentabilitas modal sendiri”.

Return on Equity adalah rasio untuk mengukur kemampuan perusahaan dalam menghasilkan keuntungan dari modal sendiri yang dimiliki perusahaan. Berikut ini adalah tabel perkembangan Return on Equity pada perusahaan periode tahun 2018-2020:

Tabel 8. Perkembangan Return On Equity

\begin{tabular}{|c|l|c|c|c|c|c|}
\hline Tahun & $\begin{array}{c}\text { Laba Bersih setelah } \\
\text { pajak } \\
(\mathrm{Rp})\end{array}$ & $\begin{array}{c}\mathrm{N} / \mathrm{T} \\
(\%)\end{array}$ & $\begin{array}{c}\text { Equity } \\
(\mathrm{Rp})\end{array}$ & $\begin{array}{c}\mathrm{N} / \mathrm{T} \\
(\%)\end{array}$ & $\begin{array}{c}\text { Return On } \\
\text { Equity } \\
(\%)\end{array}$ & $\begin{array}{c}\mathrm{N} / \mathrm{T} \\
(\%)\end{array}$ \\
\hline 2018 & $\mathrm{Rp} 1.663 .000 .000 .000$ & - & $\mathrm{Rp} 24.747 .000 .000 .000$ & - & $6.7 \%$ & - \\
\hline 2019 & $\mathrm{Rp}(2.061 .000 .000 .000)$ & $(224)$ & $\mathrm{Rp} 34.377 .000 .000 .000$ & 39 & $-6.0 \%$ & $(0.127)$ \\
\hline 2020 & $\mathrm{Rp}(1.950 .296 .000 .000)$ & $(5)$ & $\mathrm{Rp} 31.871 .516 .000 .000$ & $(7)$ & $-6.1 \%$ & $(0.001)$ \\
\hline
\end{tabular}

Sumber : Laporan Keuangan Lippo Karawaci Tbk Th. 2018-2020

Berdasarkan tabel perkembangan Return on Equity di atas bahwa selama periode tahun 2018 sampai dengan 2020 mengalami penurunan. Bisa dikatakan bahwa faktor yang menyebabkan rendahnya Return On Equity perusahaan disebabkan oleh besarnya modal sendiri perusahaan tanpa disertai kenaikan laba yang tinggi. Kesimpulannya, mengenai perkembangan Return on Equity pada perusahaan Lippo Karawaci yang selalu mengalami penurunan yang disebabkan oleh besarnya modal sendiri tanpa disertai kenaikan laba bersih yang tinggi, maka sebaiknya perusahaan harus meningkatkan laba bersih dengan cara menaikkan pendapatan dan meminimalisir biaya yang digunakan karena mengingat bahwa biaya yang dikeluarkan oleh perusahaan setiap tahunnya mengalami kenaikan.

\subsection{Faktor-Faktor yang mempengaruhi Rasio Manajamen Asset Atau Rasio Aktivitas}

Menurut Susan (2006:52) rasio manajemen asset atau sering disebut rasio aktivitas merupakan rasio yang digunakan untuk mengukur seberapa besar efektivitas perusahaan dalam memanfaatkan sumber dananya." Rasio aktivitas yang digunakan dalam penelitian ini adalah perputaran modal kerja. Menurut Kasmir (2008:182) menyatakan bahwa: "Perputaran modal kerja merupakan salah satu rasio untuk mengukur atau menilai keefektifan modal kerja 
perusahaan selama periode tertentu. Artinya seberapa banyak modal kerja berputar selama suatu periode atau dalam suatu periode".

Untuk menghitung rasio aktivitas yaitu dengan menggunakan perputaran modal kerja. Perputaran modal kerja adalah kemampuan modal kerja yang berputar dalam satu periode tertentu dari suatu perusahaan. Perputaran modal kerja merupakan salah satu rasio untuk mengukur atau menilai keefektifan modal kerja perusahaan selama periode tertentu. Modal kerja selalu dalam keadaan operasi atau berputar dalam perusahaan yang bersangkutan dalam keadaan usaha. Periode perputaran modal kerja (working capital turnover periode) dimulai dari saat dimana kas diinvestasikan dalam komponen-komponen modal kerja sampai saat dimana kembali lagi ke kas.

Semakin tinggi tingkat perputarannya, maka penggunaannnya semakin efektif, sehingga periode terikatnya modal kerja semakin pendek dan jumlah modal kerja yang dibutuhkan semakin kecil. Sebaliknya, semakin rendah tingkat perputarannya, maka penggunaannya semakin tidak efektif, sehingga periode terikatnya modal kerja semakin panjang dan jumlah modal kerja yang dibutuhkan semakin besar untuk membiayai kegiatan perusahaan (Riyanto, 2010). Di bawah ini disajikan tabel perputaran modal kerja :

Tabel 9. Perkembangan perputaran modal kerja

\begin{tabular}{|c|c|c|c|c|c|c|}
\hline Tahun & \multicolumn{1}{|c|}{$\begin{array}{c}\text { Penjualan } \\
(\mathrm{Rp})\end{array}$} & $\begin{array}{c}\mathrm{N} / \mathrm{T} \\
(\%)\end{array}$ & $\begin{array}{c}\text { Rata-rata MK } \\
(\mathrm{Rp})\end{array}$ & $\begin{array}{c}\mathrm{N} / \mathrm{T} \\
(\%)\end{array}$ & $\begin{array}{c}\text { Perputaran MK } \\
(\%)\end{array}$ & $\begin{array}{c}\mathrm{N} / \mathrm{T} \\
(\%)\end{array}$ \\
\hline 2018 & $\mathrm{Rp} \mathrm{11.453.000.000.000}$ & - & $\mathrm{Rp} \mathrm{24.842.000.000.000}$ & - & 0.46 & - \\
\hline 2019 & $\mathrm{Rp} \mathrm{12.320.000.000.000}$ & 8 & $\mathrm{Rp} \mathrm{30.316.000.000.000}$ & 22 & 0.41 & $(0.05)$ \\
\hline 2020 & $\mathrm{Rp} \mathrm{3.100.671.000.000}$ & $(75)$ & $\mathrm{Rp} \mathrm{39.189.618.000.000}$ & 29 & 0.08 & $(0.33)$ \\
\hline
\end{tabular}

Sumber : Laporan Keuangan Lippo Karawaci Tbk Th. 2018-2020

Berdasarkan tabel perkembangan perputaran modal kerja pada perusahaan dari tahun 2018 sampai dengan 2020 selalu mengalami penurunan setiap tahunnya. Perputaran modal kerja tertinggi tercapai pada tahun 2018 yaitu sebanyak 0.46 kali sedangkan yang terendah terjadi pada tahun 2020 yaitu sebanyak 0.08 kali. Perputaran modal kerja pada tahun 2019-2020 samasama mengalami penurunan disebabkan oleh peningkatan rata-rata modal kerja lebih besar dibandingkan dengan peningkatan penjualan. Kesimpulannya, untuk dapat lebih meningkatkan tingkat perputaran modal kerja, pihak perusahaan harus dapat lebih meningkatkan tingkat pendapatannya. Perlu juga dipertimbangkan oleh pihak perusahaan untuk bisa meningkatkan usaha dari tersedianya jumlah modal yang ada.

\section{KESIMPULAN}

Berdasarkan hasil penelitian dan analisis yang dilakukan mengenai evaluasi faktor-faktor yang mempengaruhi kinerja keuangan di perusahaan Lippo Karawaci Tbk maka dapat disimpulkan sebagai berikut: Tingkat likuiditas perusahaan Lippo Karawaci Tbk tergolong cukup baik, sebaiknya secara operasional perusahaan tersebut harus mampu mengendalikan likuiditas agar mencapai kriteria likuid dengan cara mengurangi piutang, karena mengingat bahwa proporsi piutang pada komponen aset lancar paling besar. Hal ini dimaksudkan agar perusahaan memperoleh dana untuk membiayai kegiatan operasional perusahaan sehari-hari dan untuk membayar kewajibannya sehingga tidak menurunkan profitabilitas perusahaan. Dari segi tingkat rasio pengukuran struktur modal kondisi perkembangan perusahaan Lippo Kara- 
waci sudah cukup baik, namun sebaiknya perusahaan memperhatikan upaya dan strategi untuk menentukan proporsi struktur modal yang baik, salah satunya dengan mempertahankan jumlah modal agar nilainya selalu berada diatas jumlah hutang yang dimiliki oleh perusahaan, agar mampu memenuhi segala kewajiban-kewajiban yang harus ditanggung oleh perusahaan. Perkembangan Return on Equity pada perusahaan Lippo Karawaci yang selalu mengalami penurunan yang disebabkan oleh besarnya modal sendiri tanpa disertai kenaikan laba bersih yang tinggi, maka sebaiknya perusahaan harus meningkatkan laba bersih dengan cara menaikkan pendapatan dan meminimalisir biaya yang digunakan karena mengingat bahwa biaya yang dikeluarkan oleh perusahaan setiap tahunnya mengalami kenaikan. Untuk dapat lebih meningkatkan tingkat perputaran modal kerja, pihak perusahaan harus dapat lebih meningkatkan tingkat pendapatannya. Perlu juga dipertimbangkan oleh pihak perusahaan untuk bisa meningkatkan usaha dari tersedianya jumlah modal yang ada. Perputaran modal kerja yang rendah menunjukkan adanya kelebihan modal kerja yang disebabkan saldo bank yang terlalu besar.

\section{Referensi}

Djuhana, D. (2009). Pasar Uang dan Pasar Modal. Garut: Ikhwan PC

Fahmi, I. (2011). Analisis Kinerja Kenangan Panduan bagi Akademis, Manajer, dan Investor untuk Menilai dan Menganalisis Bisnis dari Aspek Kenangan. Edisi Kesatu. Bandung: Alfabeta.

Kasmir. (2008). Analisis Laporan Kenangan. Jakarta: Raja Grafindo Persada

Kesuma, A. (2009). Analisis Faktor Yang Mempengaruhi Struktur Modal Serta Pengaruhnya Terhadap Harga Saham Perusahaan Real Estate Yang Go Public Di Bursa Efek Indonesia. Jurnal Manajemen Dan Kewirausabaan, Vol.11, No. 1, 38-45.

Riyanto, B. (2001). Dasar-dasar Pembelanjaan Perusahaan. Yogyakarta: BPFE UGM

Susan, I. (2006). Manajemen Keuangan. Bandung: Pustaka

Sutrisno. 2003. Manajemen Keuangan Teori, Konsep dan Aplikasi. Edisi Pertama. Yogyakarta: Ekonisia.

Syahrial, D. \& Purba, D. (2013). Analisis Laporan Keuangan. Edisi 2. Jakarta: Mitra Wacana Media

Werner R. Murhadi. (2013). Analisis Laporan Kenangan Lanjutan Proyeksi dan Valuasi Saham. Jakarta : Salemba Empat. 